Annales Geophysicae (2001) 19: 783-796 (c) European Geophysical Society 2001

\title{
Equinoctial transitions in the ionosphere and thermosphere
}

\author{
A. V. Mikhailov ${ }^{1}$ and K. Schlegel ${ }^{2}$ \\ ${ }^{1}$ Institute of Terrestrial Magnetism, Ionosphere and Radio Wave Propagation, Troitsk, Moscow Region 142190, Russia \\ ${ }^{2}$ Max-Planck-Institut für Aeronomie, Max-Planck-Str.2, 37191 Katlenburg-Lindau, Germany
}

Received: 6 November 2000 - Revised: 3 May 2001 - Accepted: 16 May 2001

\begin{abstract}
Equinoctial summer/winter transitions in the parameters of the F2-region are analyzed using ground-based ionosonde and incoherent scatter observations. Average transition from one type of diurnal $\mathrm{NmF} 2$ variation to another takes 20-25 days, but cases of very fast (6-10 days) transitions are observed as well. Strong day-time NmF2 deviations of both signs from the monthly median, not related to geomagnetic activity, are revealed for the transition periods. Both longitudinal and latitudinal variations take place for the amplitude of such quiet time NmF2 deviations. The summertype diurnal $\mathrm{NmF} 2$ variation during the transition period is characterized by decreased atomic oxygen concentration [O] and a small equatorward thermospheric wind compared to winter-type days with strong poleward wind and increased [O]. Molecular $\mathrm{N}_{2}$ and $\mathrm{O}_{2}$ concentrations remain practically unchanged in such day-to-day transitions. The main cause of the F2-layer variations during the transition periods is the change of atomic oxygen abundance in the thermosphere related to changes of global thermospheric circulation. A possible relationship with an equinoctial transition of atomic oxygen at the E-region heights is discussed.
\end{abstract}

Key words. Atmospheric composition and structure (thermosphere - composition and chemistry) - Ionosphere (ionosphere-atmosphere interactions; ionospheric disturbances)

\section{Introduction}

Two types of diurnal $f o \mathrm{~F} 2$ variation (winter and summer) have been known for many years (e.g. Yonezawa, 1959). Evans, in the late $60 \mathrm{~s}$, was probably the first to show the effect of equinoctial transitions in the F2-region parameters using Millstone Hill incoherent scatter observations; he proposed a relationship of this effect with changes in the global thermospheric circulation (Evans, 1970, 1973, 1974). According to his observations the main differences between the winter and summer F2-region are the following:

Correspondence to: K. Schlegel (schlegel@linmpi.mpg.de)
1) large diurnal $\mathrm{NmF} 2$ variations in winter (up to an order of magnitude), while in summer the $\mathrm{NmF} 2$ day/night ratio is only about a factor of 2 ;

2) the maximum in the diurnal $\mathrm{NmF} 2$ variations takes place around $13 \mathrm{LT}$ in winter, while in summer it shifts towards 18-20 LT, a morning peak can frequently occur;

3) summer day-time $h m F 2$ values are higher by about 20 $\mathrm{km}$ and in summer the layer is broader than in winter for the same geophysical conditions.

The transition in the diurnal variations of $\mathrm{NmF} 2$ and $h m \mathrm{~F} 2$ from one type to the other is very rapid and occurs during a couple of weeks around equinoxes. The differences mentioned above are supposed to reflect strong changes in neutral composition and thermospheric winds during the transition periods.

Global modelling of the thermosphere by Fuller-Rowell and Rees (1983) confirmed seasonal changes of neutral composition caused by global circulation in the thermosphere. Rishbeth and Müller-Wodarg (1999), using a 3D model of the thermosphere, confirmed that seasonal changes take place quite quickly around equinoxes, essentially between February and April and between August and October. Shepherd et al. (1999) using ground-based and optical satellite observations revealed strong variations in the integrated emission rate for the oxygen airglow during the springtime transition period. An increase by a factor of $2-3$ in the emission rate was followed by a strong decrease by a factor of 10 down to the summer time level for the oxygen emission rate. This enhancement appears as a pulse that passes a given ground station only once; this pulse may be considered as a large planetary scale feature. WINDII emission rate profiles show that this planetary scale feature is accompanied by strong vertical air motions. So, there are theoretical and experimental indications of strong and sudden changes in the thermospheric circulation pattern around equinoxes and related changes in neutral composition.

The aim of the present study is to consider the morphology of equinoctial $f o \mathrm{~F} 2$ transitions using world-wide groundbased ionosonde data. In addition, incoherent scatter (IS) 

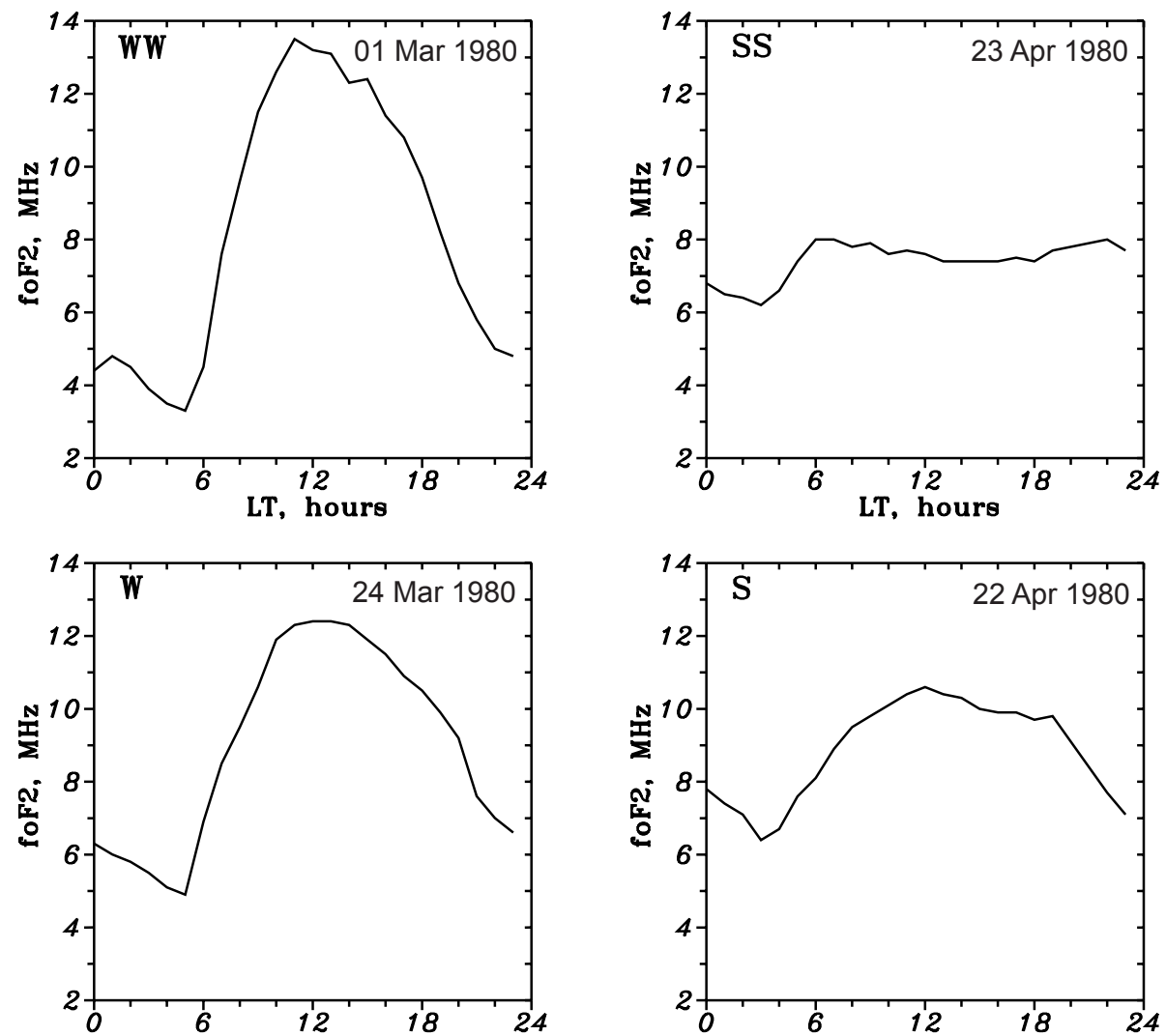

LT, hours
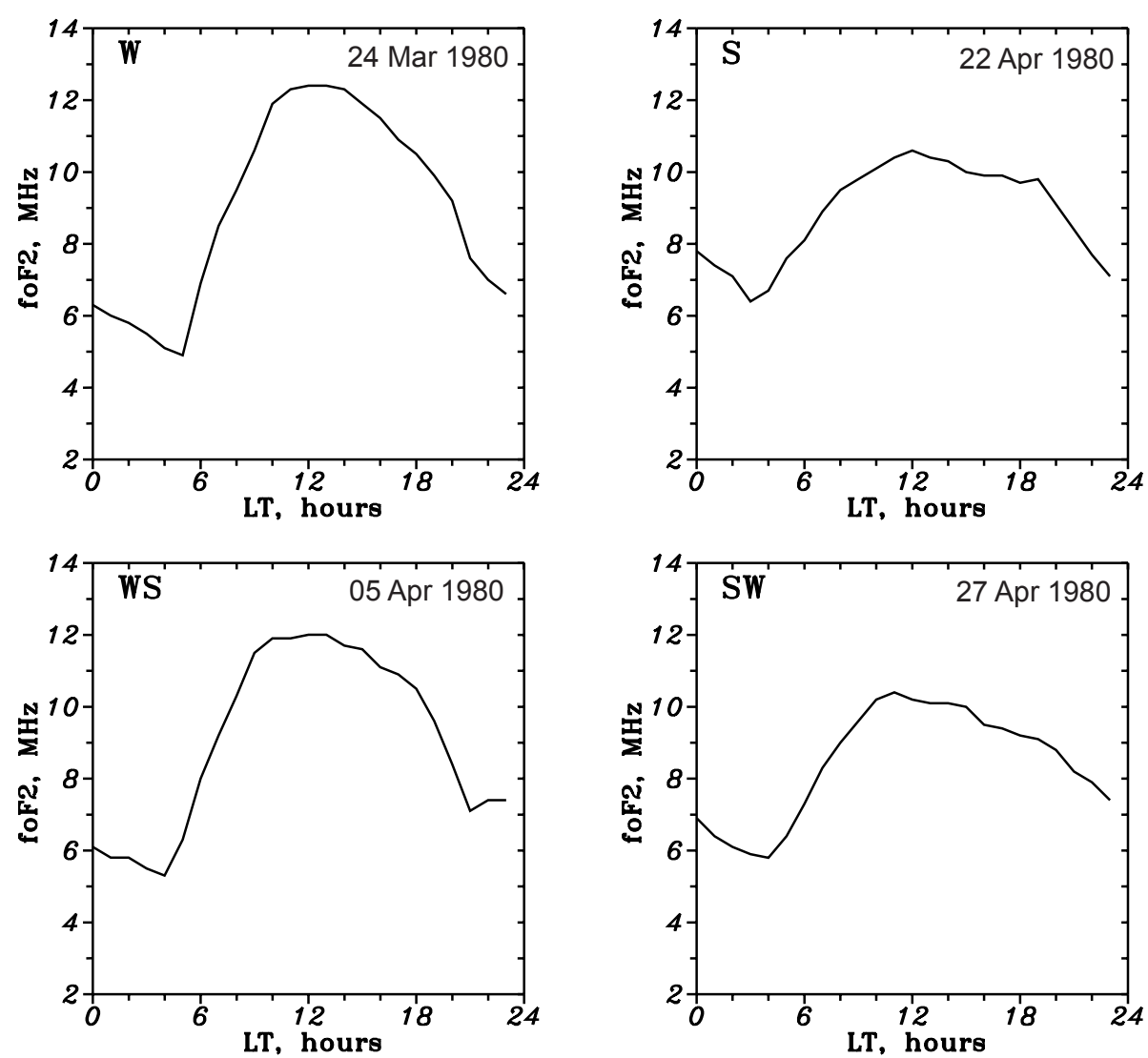

Fig. 1. Typical winter- and summertype diurnal $f o \mathrm{~F} 2$ variations observed at Moscow in 1980 and used to specify the dates of winter/summer transitions.
Table 1. Ionosonde stations used in the study

\begin{tabular}{lccc}
\hline Ionosonde station & Geog. lat., $N$ & Geog. long., E & Magn. lat. \\
\hline Sodankylä & 67.4 & 26.6 & 63.7 \\
St. Petersburg & 60.0 & 30.7 & 56.2 \\
Moscow & 55.5 & 37.3 & 50.8 \\
Irkutsk & 52.5 & 104.0 & 41.4 \\
Alma-Ata & 43.2 & 76.9 & 33.4 \\
Boulder & 40.0 & 254.7 & 48.9 \\
\hline
\end{tabular}

observations from Millstone Hill and EISCAT, for selected transition periods with winter and summer types of diurnal
$\mathrm{NmF} 2$ variations, are analyzed to reveal the differences in neutral composition, temperature, and winds.

\section{Morphology of the foF2 transitions}

The equinoctial foF2 transition morphology was analyzed using daily foF2 variations at six ionosonde stations (Table 1) which allow us to consider both the latitudinal and longitudinal formation of the effect in question. Years of solar minimum $(1964,1975,1985)$ and maximum $(1959,1969,1980)$ from three different solar cycles were analyzed to check the solar activity dependence. Both characteristics, foF 2 and $\mathrm{NmF} 2=1.24 \times 10^{4}(f o \mathrm{~F} 2)^{2}$, are used in the paper to de- 
Table 2.1. Start and end dates of the equinoctial transitions for the latitudinal chain of stations during solar minimum. Dashes indicate missing or poor observations

\begin{tabular}{|c|c|c|c|c|c|c|c|c|c|}
\hline \multirow[t]{2}{*}{ Years } & \multicolumn{3}{|c|}{ Sodankylä } & \multicolumn{3}{|c|}{ St. Petersburg } & \multicolumn{3}{|c|}{ Alma-Ata } \\
\hline & Start & End & Days & Start & End & Days & Start & End & Days \\
\hline 1964 spr & $15 \mathrm{Mar}$ & $29 \mathrm{Apr}$ & 45 & $15 \mathrm{Mar}$ & 14 Apr & 30 & 19 Mar & $18 \mathrm{Apr}$ & 30 \\
\hline 1964 aut & 03 Sep & $12 \mathrm{Oct}$ & 39 & 09 Sep & 11 Oct & 32 & $15 \mathrm{Sep}$ & 30 Sep & 15 \\
\hline $1975 \mathrm{spr}$ & - & - & - & $21 \mathrm{Mar}$ & $01 \mathrm{Apr}$ & 11 & $16 \mathrm{Mar}$ & $30 \mathrm{Apr}$ & 45 \\
\hline 1975 aut & 08 Sep & 05 Oct & 27 & $14 \mathrm{Sep}$ & 04 Oct & 20 & $08 \mathrm{Sep}$ & $12 \mathrm{Oct}$ & 34 \\
\hline $1985 \mathrm{spr}$ & 04 Mar & 01 May & 57 & $21 \mathrm{Mar}$ & $05 \mathrm{Apr}$ & 15 & 26 Mar & 01 May & 35 \\
\hline 1985 aut & - & 02 Oct & - & 22 Sep & 08 Oct & 16 & 04 Sep & 08 Oct & 34 \\
\hline
\end{tabular}

Table 2.2. Same as Table 2.1, but for solar maximum

\begin{tabular}{|c|c|c|c|c|c|c|c|c|c|}
\hline \multirow[t]{2}{*}{ Years } & \multicolumn{3}{|c|}{ Sodankylä } & \multicolumn{3}{|c|}{ St. Petersburg } & \multicolumn{3}{|c|}{ Alma-Ata } \\
\hline & Start & End & Days & Start & End & Days & Start & End & Days \\
\hline $1959 \mathrm{spr}$ & - & - & - & - & - & - & $?$ & $?$ & - \\
\hline 1959 aut & - & - & - & $16 \mathrm{Sep}$ & 29 Sep & 13 & $?$ & $?$ & - \\
\hline $1969 \mathrm{spr}$ & 28 Mar & 17 Apr & 20 & $25 \mathrm{Mar}$ & $11 \mathrm{Apr}$ & 17 & $20 \mathrm{Mar}$ & $25 \mathrm{Apr}$ & 35 \\
\hline 1969 aut & 04 Sep & 05 Oct & 31 & 20 Sep & 06 Oct & 16 & $11 \mathrm{Sep}$ & 01 Oct & 20 \\
\hline $1980 \mathrm{spr}$ & $24 \mathrm{Mar}$ & $13 \mathrm{Apr}$ & 20 & 25 Mar & 07 Apr & 13 & $24 \mathrm{Mar}$ & $06 \mathrm{Apr}$ & 13 \\
\hline 1980 aut & $22 \mathrm{Sep}$ & 03 Oct & 11 & 23 Sep & 03 Oct & 10 & $20 \mathrm{Sep}$ & 08 Oct & 18 \\
\hline
\end{tabular}

scribe the variation of the maximum electron concentration of the F2-layer. Six different types of diurnal foF2 variation are introduced (Fig. 1):

- WW - well-pronounced winter-type diurnal NmF2 variation with:

(1) very large diurnal $\mathrm{NmF} 2$ variation with the $\mathrm{NmF} 2_{\max } /$ $\mathrm{NmF} 2_{\text {min }}$ ratio larger than an order of magnitude;

(2) well-developed diurnal maximum of $\mathrm{NmF} 2$ around 12-13 LT followed by a steep decrease of NmF2 towards evening hours;

(3) relatively narrow $\mathrm{NmF} 2$ day-time variation;

- SS - well-pronounced summer-type diurnal NmF2 variation with:

(1) small plateau-like diurnal $\mathrm{NmF} 2$ variation with a $\mathrm{NmF} 2_{\text {max }} / \mathrm{NmF} 2_{\text {min }}$ ratio less then two;

(2) two (morning and evening) NmF2 maxima and a dip around noon;

(3) very broad $\mathrm{NmF} 2$ day-time variation;

- $\mathrm{W}$ - normal winter-type diurnal $\mathrm{NmF} 2$ variation with:

(1) large diurnal $\mathrm{NmF} 2$ variation with about an order of magnitude $\mathrm{NmF} 2_{\text {max }} / \mathrm{NmF} 2_{\text {min }}$ ratio;

(2) diurnal NmF2 peak around 12-13 LT followed by relatively steep $\mathrm{NmF} 2$ decrease towards evening hours;

(3) relatively small width of the $\mathrm{NmF} 2$ day-time variation;
- $\mathrm{S}$ - normal summer-type diurnal $\mathrm{NmF} 2$ variation with:

(1) small diurnal $\mathrm{NmF} 2$ variation with $\mathrm{NmF}_{2}$ max $\mathrm{NmF} 2$ min about $2-3$;

(2) flat day-time $\mathrm{NmF} 2$ variation with a developed evening peak and a gently sloping NmF2 decrease towards night-time hours;

(3) broad NmF2 day-time variation;

- WS and SW - intermediate types of the NmF2 variation in which winter or summer features prevail.

Unfortunately, the observed $f_{o} \mathrm{~F} 2$ variations cannot always be classified according to the above scheme. Boulder, for instance, exhibits summer foF2 variations with one wellpronounced maximum around noon as in winter. A similar type of variation takes place at Alma-Ata during solar maximum. This impedes a specification of the dates for winter/summer transitions. The other characteristics (width of the $\mathrm{NmF} 2$ day-time variation, $\mathrm{NmF} 2_{\max } / \mathrm{NmF} 2_{\text {min }}$ ratio) are used in these cases to specify the type. Perturbations of the F2-layer, due to geomagnetic disturbances (especially prolonged), also mask the date of transitions but the analysis has shown that, usually, the transition period ends with a geomagnetic storm after which a new type of the diurnal foF2 variation is established. Thus, F2-layer storms seem to help in changing the type of diurnal variation.

The start and end dates of vernal and autumnal transitions at 6 stations are given in Tables 2 and 3 for years of solar minimum and maximum. The stations are grouped according to latitudinal (Tables 2.1 and 2.2) and longitudinal (Tables 3.1 and 3.2) variations. Observations are missing for some periods (dashes) while only winter-type foF2 variations took 
Table 3.1. Start and end dates of the equinoctial transitions for the longitudinal chain of stations during solar minimum

\begin{tabular}{|c|c|c|c|c|c|c|c|c|c|}
\hline \multirow[t]{2}{*}{ Years } & \multicolumn{3}{|c|}{ Moscow } & \multicolumn{3}{|c|}{ Irkutsk } & \multicolumn{3}{|c|}{ Boulder } \\
\hline & Start & End & Days & Start & End & Days & Start & End & Days \\
\hline 1964 spr & $16 \mathrm{Mar}$ & 09 Apr & 24 & $19 \mathrm{Mar}$ & $07 \mathrm{Apr}$ & 19 & 13 Mar & $22 \mathrm{Apr}$ & 40 \\
\hline 1964 aut & $21 \mathrm{Sep}$ & 04 Oct & 13 & 19 Sep & $01 \mathrm{Oct}$ & 12 & 29 Sep & 05 Oct & 7 \\
\hline $1975 \mathrm{spr}$ & $19 \mathrm{Mar}$ & $01 \mathrm{Apr}$ & 13 & 22 Mar & $17 \mathrm{Apr}$ & 26 & 19 Mar & $01 \mathrm{Apr}$ & 13 \\
\hline 1975 aut & $11 \mathrm{Sep}$ & 06 Oct & 25 & $21 \mathrm{Sep}$ & 07 Oct & 16 & 14 Sep & 04 Oct & 20 \\
\hline $1985 \mathrm{spr}$ & $21 \mathrm{Mar}$ & $31 \mathrm{Mar}$ & 10 & 22 Mar & $13 \mathrm{Apr}$ & 22 & 17 Mar & $05 \mathrm{Apr}$ & 19 \\
\hline 1985 aut & $17 \mathrm{Sep}$ & 08 Oct & 21 & $21 \mathrm{Sep}$ & $27 \mathrm{Sept}$ & 6 & 08 Sep & $13 \mathrm{Oct}$ & 35 \\
\hline
\end{tabular}

Table 3.2. Same as Table 3.1, but for solar maximum

\begin{tabular}{|c|c|c|c|c|c|c|c|c|c|}
\hline \multirow[t]{2}{*}{ Years } & \multicolumn{3}{|c|}{ Moscow } & \multicolumn{3}{|c|}{ Irkutsk } & \multicolumn{3}{|c|}{ Boulder } \\
\hline & Start & End & Days & Start & End & Days & Start & End & Days \\
\hline $1959 \mathrm{spr}$ & $16 \mathrm{Mar}$ & 17 Apr & 32 & $01 \mathrm{Apr}$ & 01 May & 30 & $01 \mathrm{Apr}$ & $13 \mathrm{Apr}$ & 12 \\
\hline 1959 aut & 13 Sep & $26 \mathrm{Sep}$ & 13 & 09 Sep & $26 \mathrm{Sep}$ & 17 & - & - & - \\
\hline 1969 spr & 27 Mar & $23 \mathrm{Apr}$ & 27 & 20 Mar & $09 \mathrm{Apr}$ & 20 & $02 \mathrm{Apr}$ & $20 \mathrm{Apr}$ & 18 \\
\hline 1969 aut & $21 \mathrm{Sep}$ & 02 Oct & 11 & $16 \mathrm{Sep}$ & $02 \mathrm{Oct}$ & 16 & $17 \mathrm{Sep}$ & $10 \mathrm{Oct}$ & 23 \\
\hline $1980 \mathrm{spr}$ & $25 \mathrm{Mar}$ & $12 \mathrm{Apr}$ & 17 & $23 \mathrm{Mar}$ & $13 \mathrm{Apr}$ & 21 & $30 \mathrm{Mar}$ & $20 \mathrm{Apr}$ & 21 \\
\hline 1980 aut & $23 \mathrm{Sep}$ & $03 \mathrm{Oct}$ & 10 & - & $05 \mathrm{Oct}$ & - & 02 Sep & 05 Oct & 33 \\
\hline
\end{tabular}

place at Alma-Ata during 1959 and the transition dates could not be detected (marked by ? in Table 2.2). On average the transitions occur during 20-25 days although the vernal transition lasts a little longer than the autumnal one. The vernal transition is seen to start very close to the equinoctial date while the autumnal one starts earlier. Both transitions start a little earlier at solar minimum and last longer compared to solar maximum (Table 4).

Although the mean transition lasts around three weeks there are cases of very fast change-over. For instance, 1964: autumn Boulder (7 days), 1985: spring Moscow (10 days) and Irkutsk autumn (6 days), 1980: autumn St. Petersburg (10 days), Sodankylä (11 days), Moscow (10 days) (Tables 2 and 3).

As was mentioned earlier, geomagnetic disturbances mask the analyzed effect in many cases. Both equinoxes were relatively quiet in 1980; neither a pronounced latitudinal nor longitudinal variation was found for the dates and durations of the transitions within the limits of accuracy available for these parameters.

\section{Quiet-time F2-layer deviations}

During the equinoctial transitions, large deviations of $f_{o} \mathrm{~F} 2$ from the monthly median occur as will be explained in the following. The deviations can be positive or negative with respect to the monthly median and they are not related to geomagnetic activity as usual F2-layer storms. Two such examples observed at Moscow on 29 Sep 1980 and $23 \mathrm{Apr}$ 1980 are shown in Figs. 2 and 3. Daily $A p, 3$-hour $K p$, and hourly AE indices are given as well. According to commonly accepted classification, both periods can be consid-
Table 4. Start and end dates and durations averaged over all stations of the equinoctial transitions

\begin{tabular}{lllc}
\hline Period & Start date & End date & Duration, days \\
\hline Solar min & $18 \mathrm{Mar} \pm 5$ & $14 \mathrm{Apr} \pm 11$ & $27 \pm 8$ \\
& $14 \mathrm{Sep} \pm 7$ & $06 \mathrm{Oct} \pm 5$ & $22 \pm 6$ \\
Solar max & $26 \mathrm{Mar} \pm 5$ & $16 \mathrm{Apr} \pm 7$ & $21 \pm 6$ \\
& $16 \mathrm{Sep} \pm 7$ & $03 \mathrm{Oct} \pm 4$ & $17 \pm 5$ \\
All years & $21 \mathrm{Mar} \pm 6$ & $15 \mathrm{Apr} \pm 9$ & $25 \pm 7$ \\
& $15 \mathrm{Sep} \pm 7$ & $05 \mathrm{Oct} \pm 4$ & $20 \pm 5$ \\
\hline
\end{tabular}

ered as magnetically quiet. Nevertheless the day-time NmF2 deviations are very distinct - a factor of 2 in both cases. Variations of the F2-layer maximum height, $h m \mathrm{~F} 2$, calculated from the $M(3000) \mathrm{F} 2$ parameter using the Bradley-Dudeney (1973) expression, are given in Figs. 2 and 3 as well. Although the absolute accuracy of such an $h m \mathrm{~F} 2$ determination may be not very high, relative (daily) variations can be considered as reliable. Average day-time F2-layer heights are indicated in Figs. 2 and 3 as thin lines. Some day-today $h m \mathrm{~F} 2$ variations can be seen but these differences in the average $h m \mathrm{~F} 2$ may be not meaningful keeping in mind the large fluctuations of the hourly $h m \mathrm{~F} 2$ values. The most interesting result is a relatively small daily $h m \mathrm{~F} 2$ change while the NmF2 day-to-day variations are large. This peculiarity of $\mathrm{NmF} 2$ and $h m \mathrm{~F} 2$ daily variations is discussed later using IS observations. It should be stressed that such NmF2 and $h m \mathrm{~F} 2$ behavior is never observed at midlatitudes during F2layer storms resulting from geomagnetic disturbances.

All available foF2 observations at Moscow (1958-1988) 

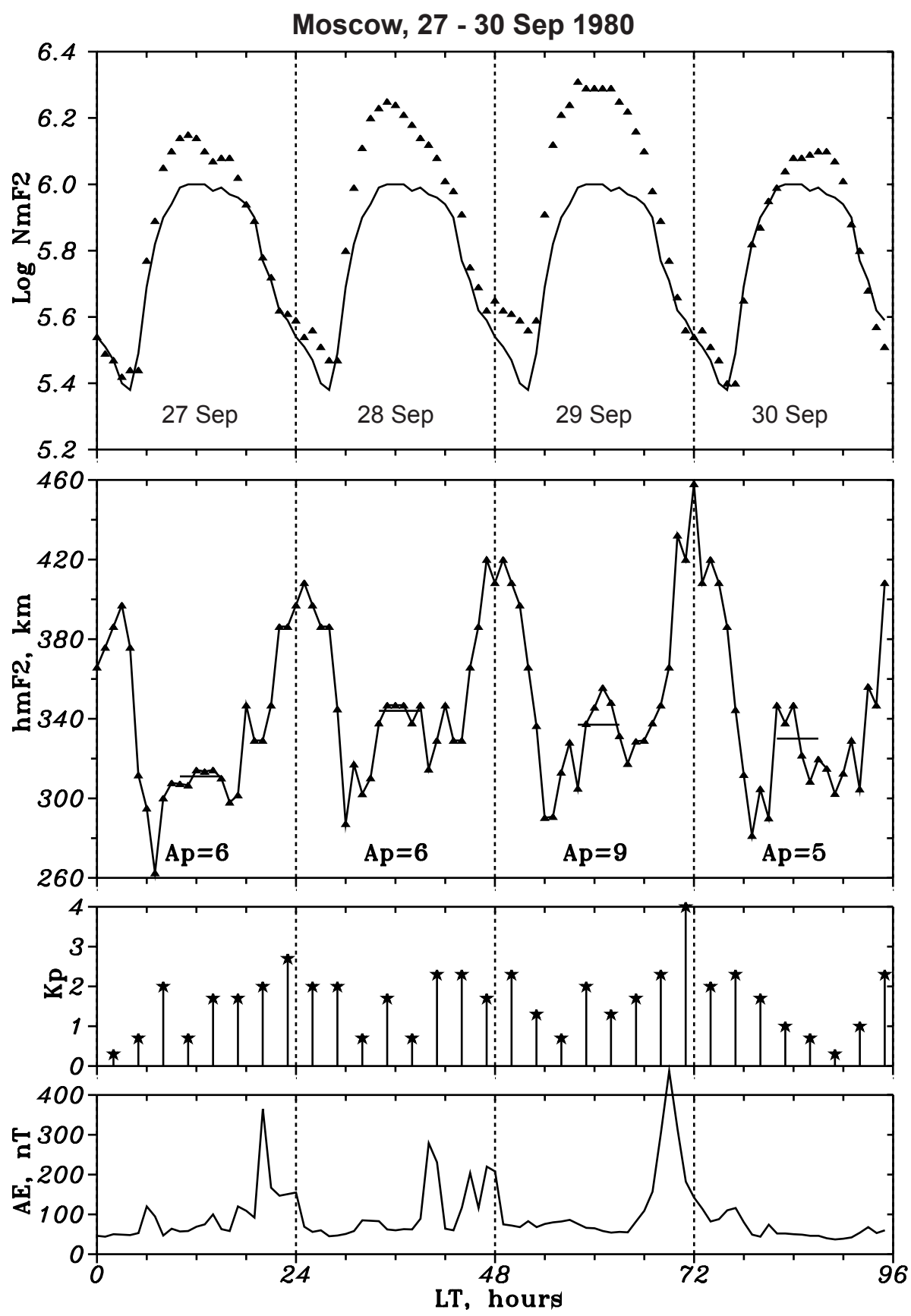

Fig. 2. An example of strong positive quiet-time NmF2 deviations observed at Moscow in September 1980. Monthly median NmF2 is shown as solid line (top panel). Diurnal variations of $h m \mathrm{~F} 2$ inferred from $\mathrm{M}(3000) \mathrm{F} 2$ parameter are shown in the second panel. Averages of $h m \mathrm{~F} 2$ from 10-15 LT are shown as horizontal thin lines. Daily $A p, 3$-hour $K p$ and hourly AE indices are shown in the third and fourth panels. and St. Petersburg (1960-1989) have been analyzed. Averaged $f o \mathrm{~F} 2$ values for 12-14 LT were compared with monthly medians and cases with large (more than $40 \%$ in NmF2) deviations were considered for quiet $(A p \leq 12$ for the day and the previous day) periods. The annual distribution of these deviations is given in Fig. 4 for the two stations. Both negative and positive deviations (as well as their sum) show wellpronounced maxima around the equinoxes, manifesting the equinoctial transitions in the F2-region. Such quiet-time and relatively strong $\left(\mathrm{NmF} 2_{\text {obs }} / \mathrm{NmF}_{2}\right.$ med $\left.\geq 40 \%\right)$ deviations are not numerous (see Fig. 4). The most abundant occurred in 1960 (12/0), 1967 (5/15), 1969 (11/10), 1970 (8/15), 1974
$(12 / 0)$ where the digits in brackets give the number of positive/negative deviations. The frequency of positive and negative deviations varies from year to year but no regularity has been revealed yet. There are years $(1960,1973,1974)$ when only positive deviations took place while negative ones prevailed in 1962, 1967, 1970.

Spatial variations of the amplitude of $\mathrm{NmF} 2$ deviations were analyzed for the dates when strong effects were observed in the European sector. The ratio $R=\mathrm{NmF} 2_{\mathrm{obs}} /$ $\mathrm{NmF} 2$ med for $\mathrm{NmF} 2$ values averaged over 3 hours (12-14 LT) was calculated for a longitudinal chain of midlatitude stations (Fig. 5) for 29 Sep 1980 and 23 Apr 1980 (see Figs. 2 
Moscow, 21 - 24 Apr 1980
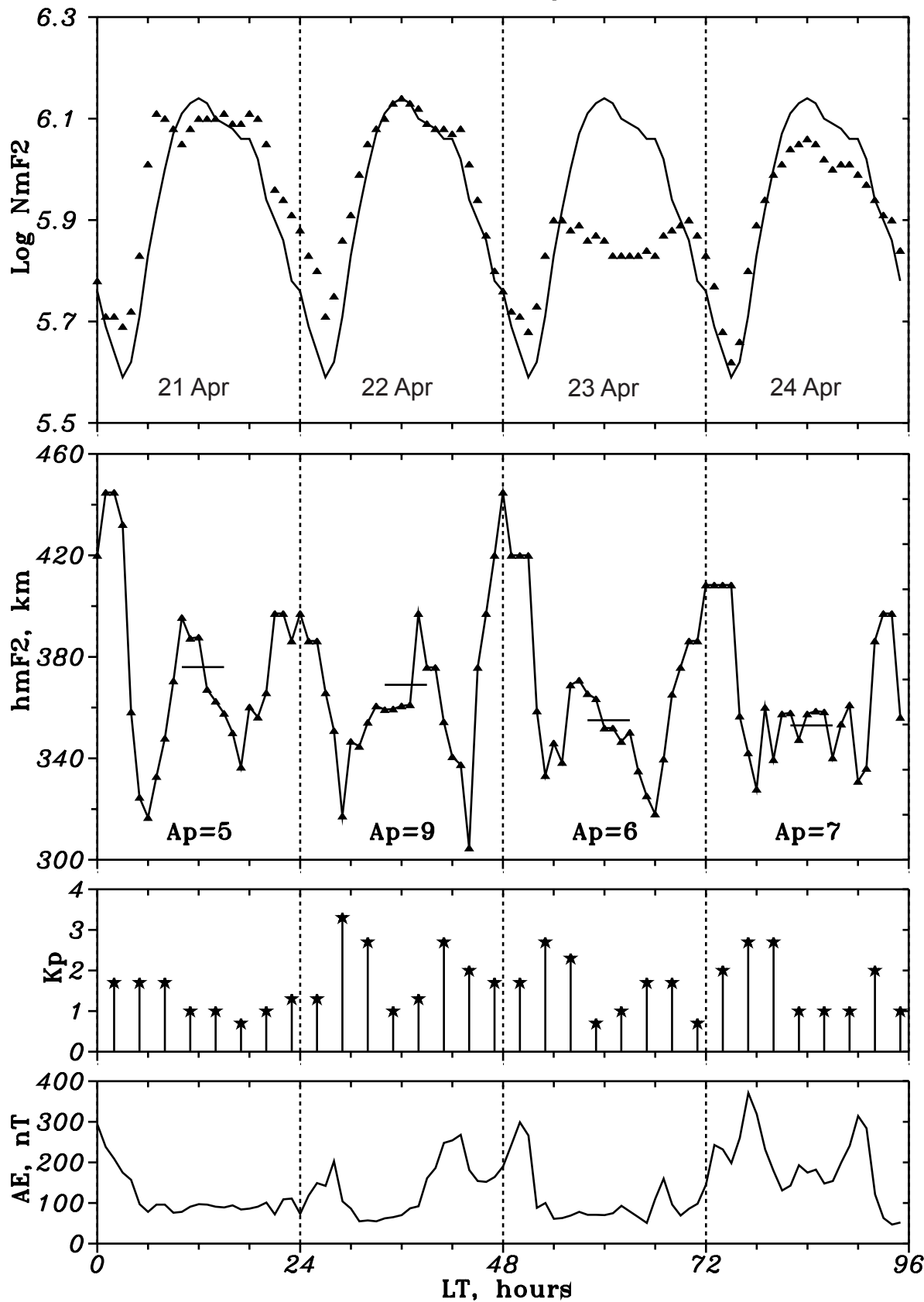

Fig. 3. Same as Fig. 2 but for a strong negative quiet time $\mathrm{NmF} 2$ deviation observed at Moscow on 23 Apr 1980. and 3). The number of available observations is not sufficient especially in the western hemisphere to draw a confident conclusion, nevertheless, the main feature of these variations is clearly seen in the European sector where the number of observations is sufficient (Fig. 5). In both cases this looks like a wave with a steep front where both maximum and minimum $R$ values are located in a narrow longitudinal interval. This behavior is similar to the springtime transition in atomic oxygen reported by Shepherd et al. (1999) who suggested a wave-like emission rate enhancement traveling westward. An additional analysis of cases similar to 29 Sep and $23 \mathrm{Apr}$ 1980 (Figs. 2 and 3) is required to consider the longitudinal dynamics of such deviations.

Latitudinal variations of $R$ in the European sector for the two days 29 Sep 1980 and 2 Apr 1992 (discussed later) with positive NmF2 deviations are shown in Fig. 6. A well-pronounced latitudinal dependence is clearly seen in both cases with the amplitude of the $\mathrm{NmF} 2$ deviation increasing with latitude.

\section{Incoherent scatter data analysis}

Incoherent scatter observations of the F2-region parameters can provide necessary information on the thermospheric 

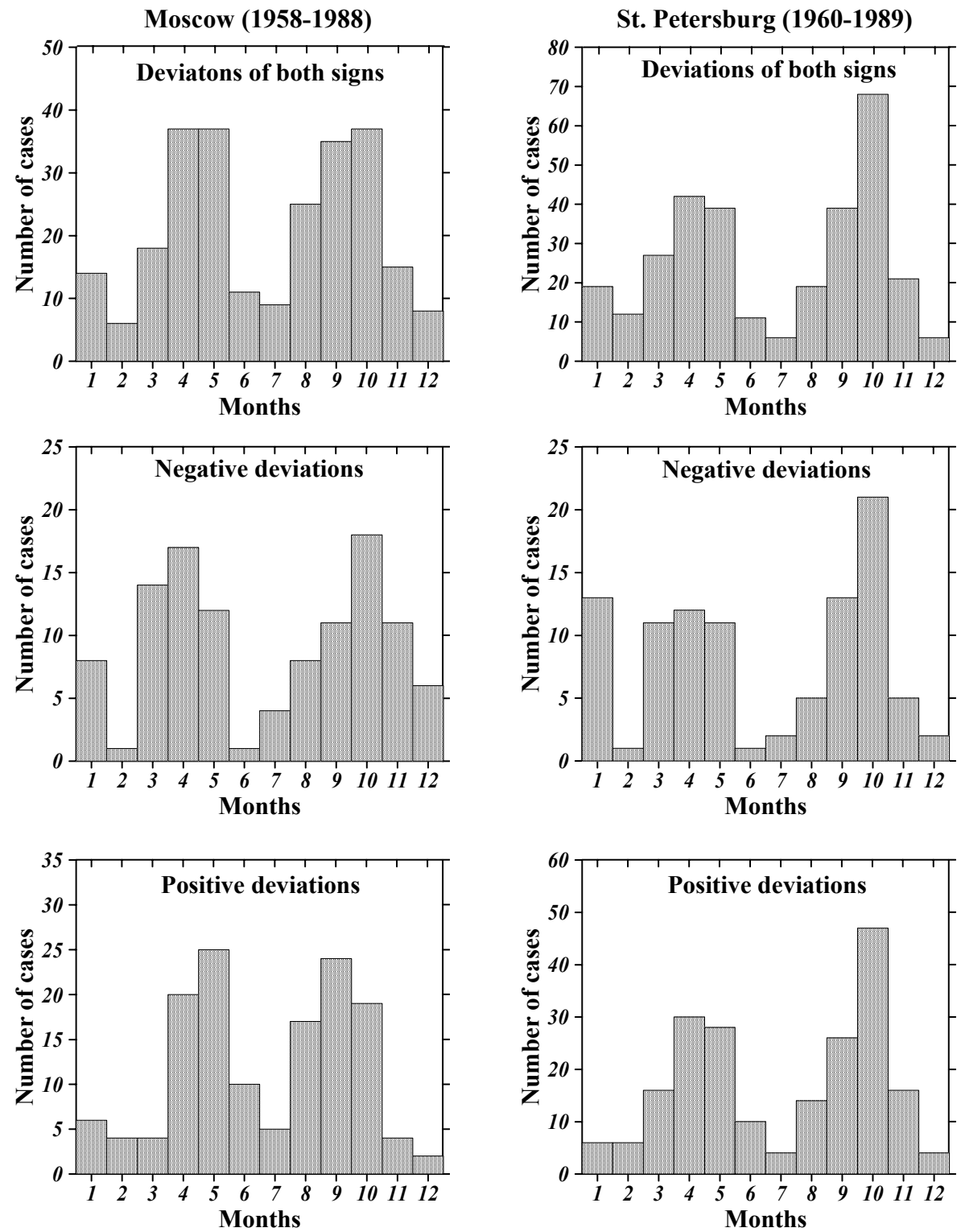
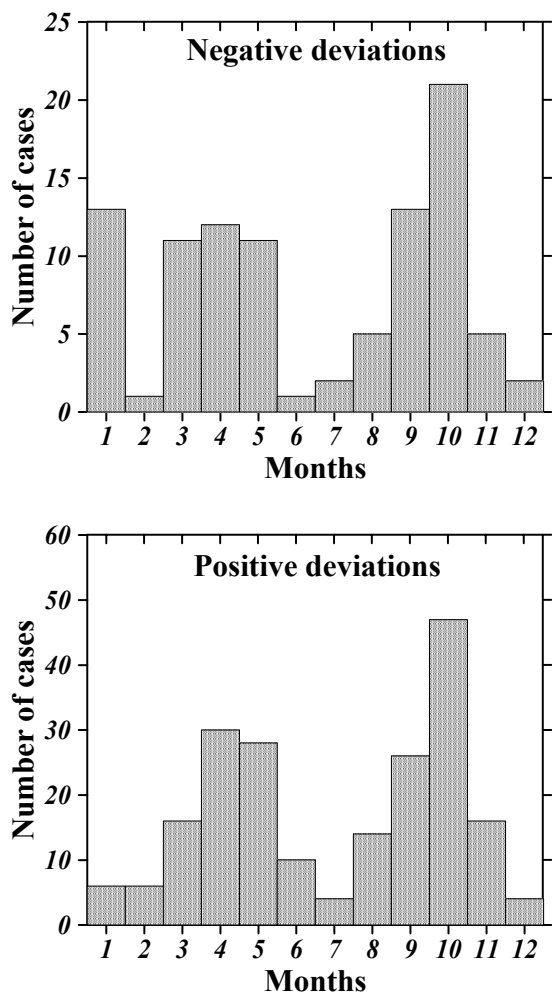

Fig. 4. Annual distribution of strong quiet-time $(A p \leq 12)$ deviations at Moscow and St. Petersburg for a 30year period. Histograms for positive, negative deviations as well as for their sum are given separately. "Strong" was defined as a NmF2 deviation $>40 \%$ from monthly median. Note the annual peaks clustering around equinoxes. changes during the equinoctial transitions. A method developed by Mikhailov and Schlegel (1997), with later modifications (Mikhailov and Förster, 1999; Mikhailov and Schlegel, 2000), applied to Millstone Hill and EISCAT observations enables us to find thermospheric neutral composition, temperature and vertical plasma drift related to the meridional neutral winds. The details of the method may be found in the above references; therefore only the main idea is sketched here. The standard set of IS observations $\left(N_{e}(h), T_{e}(h)\right.$, $T_{i}(h), V_{z}(h)$ profiles) is the initial input information. All these observed parameters are contained in the continuity equations for the main ionospheric ions in the F2-region. By fitting the calculated $N_{e}(h)$ profile to the experimental one, the set of main aeronomic parameters responsible for the observed $N_{e}(h)$ distribution can be found. The most important parameters are: neutral composition $\left(\mathrm{O}, \mathrm{O}_{2}, \mathrm{~N}_{2}\right)$, temperature $T_{n}(h)$, total EUV solar flux, ion-molecular $\left(\mathrm{O}^{+}+\mathrm{N}_{2}\right)$ reaction rate constant and vertical plasma drift $W$, resulting from the thermospheric winds and electric fields.Neutral composition, temperature and winds are the most variable parameters and they are our main concern in this study. The other important parameters such as total EUV solar flux or $\mathrm{O}^{+}+\mathrm{N}_{2}$ reaction rate coefficient may be specified once and for all as in our previous analysis (Mikhailov and Schlegel, 2000).

Let us start with typical WW and SS types of diurnal $\mathrm{NmF} 2$ variations to explore the main difference in aeronomic parameters responsible for such seasonal changes. Diurnal $\mathrm{NmF} 2$ and $h m \mathrm{~F} 2$ variations, observed during solar maximum at Millstone Hill on 12 Jan $1990\left(F_{10.7}=170.0\right.$, $F S=200.3, A p=15)$ and 26 Jun $1990\left(F_{10.7}=154.5\right.$, $F S=180.4, A p=7$ ) are shown in Fig. 7. The amplitude of the diurnal NmF2 variation is about 15 for $12 \mathrm{Jan}$, while it is only 2.5 on 26 Jun. Summer day-time (LT $=$ UT -5$)$ 
Table 5. Aeronomic parameters calculated for $300 \mathrm{~km}$ height and $12 \mathrm{LT}$ at Millstone Hill for winter and summer days. MSIS-83 model values (second line) are given for comparison

\begin{tabular}{lcccccccc}
\hline Date & $\begin{array}{c}T_{\text {ex }} \\
(\mathrm{K})\end{array}$ & $\begin{array}{c}\log [\mathrm{O}] \\
\left(\mathrm{cm}^{-3}\right)\end{array}$ & $\begin{array}{c}\log \left[\mathrm{O}_{2}\right] \\
\left(\mathrm{cm}^{-3}\right)\end{array}$ & $\begin{array}{c}\log \left[\mathrm{N}_{2}\right] \\
\left(\mathrm{cm}^{-3}\right)\end{array}$ & $\begin{array}{l}\mathrm{O} / \mathrm{N}_{2} \\
\left(\mathrm{~cm}^{-3} \mathrm{~s}^{-1}\right)\end{array}$ & $\begin{array}{c}q / 10^{3} \\
\left(\mathrm{~s}^{-1}\right)\end{array}$ & $\begin{array}{c}W \\
(\mathrm{~m} / \mathrm{s})\end{array}$ \\
\hline 12 Jan 1990 & 1142 & 8.916 & 6.828 & 8.218 & 4.99 & 1.04 & 1.81 & -10.7 \\
$\operatorname{logNmF2=6.34}$ & 1183 & 9.023 & 7.084 & 8.472 & 3.56 & & & \\
$h m \mathrm{~F} 2=282 \mathrm{~km}$ & & & & & & & & \\
\hline 26 Jun 1990 & 1234 & 8.708 & 6.959 & 8.474 & 1.71 & 0.66 & 3.05 & -1.2 \\
$\operatorname{logNmF2=5.77}$ & 1309 & 8.826 & 7.082 & 8.541 & 1.93 & & & \\
$h m \mathrm{~F} 2=290 \mathrm{~km}$ & & & & & & & & \\
\hline
\end{tabular}

$h m \mathrm{~F} 2$ values are higher than winter ones but the difference is not so large due to a higher solar activity level for the winter day. Seasonal variation of thermospheric winds and related neutral composition changes are crucial for understanding the observed seasonal difference in the F2-layer parameters (Ivanov-Kholodny and Mikhailov, 1986). The calculation procedure of Mikhailov and Schlegel (1997) uses observed smoothed day-time profiles. Due to infrequent measurements at Millstone Hill (three per hour) available for the analyzed periods, median $N_{e}(h), T_{e}(h), T_{i}(h), V_{z}(h)$ profiles were calculated over a 2.5-3.0 hour time interval centered around $12 \mathrm{LT}$ and these height profiles were used in our calculations. The derived aeronomic parameters for the two days are given in Table 5 together with F2-layer maximum parameters read from the smoothed $N_{e}(h)$ profiles.

The main difference between the winter and summer thermosphere is a decreased atomic oxygen concentration in summer (despite higher neutral temperature) and increased concentrations of molecular species. Low [O] results in lower ion production rate $q$ in summer while increased $\left[\mathrm{N}_{2}\right]$, $\left[\mathrm{O}_{2}\right]$ and temperature result in larger summer linear loss coefficient $\beta$ (Table 5). Such variations of neutral composition and temperature result, therefore, in lower summer $\mathrm{NmF} 2$ values compared to winter ones. This is a well-known F2layer seasonal anomaly (Yonezawa and Arima, 1959; Rishbeth and Setty, 1961; Torr and Torr, 1973) analyzed in detail by Ivanov-Kholodny and Mikhailov (1986). Another winter/summer difference is in vertical plasma drift, $W$, which, at midlatitudes and during quiet conditions, is mainly due to thermospheric winds. The calculated winter plasma drift corresponds to a moderate $(49 \mathrm{~m} / \mathrm{s})$ northward wind along the magnetic meridian while the corresponding summer meridional wind is close to zero. This is in line with the results of a recent wind analysis at Millstone Hill (Buonsanto and Witasse, 1999). Therefore, the winter-type F2-layer parameter variations is characterized by increased atomic oxygen concentration and northward thermospheric wind during day-time hours. On the contrary, low $[\mathrm{O}]$ and small meridional wind characterize the summer conditions. These features are important for further analysis. Increased molecular species $\mathrm{N}_{2}$ and $\mathrm{O}_{2}$ concentrations in the summer F2-region are mainly due to higher neutral temperature (Table 5).
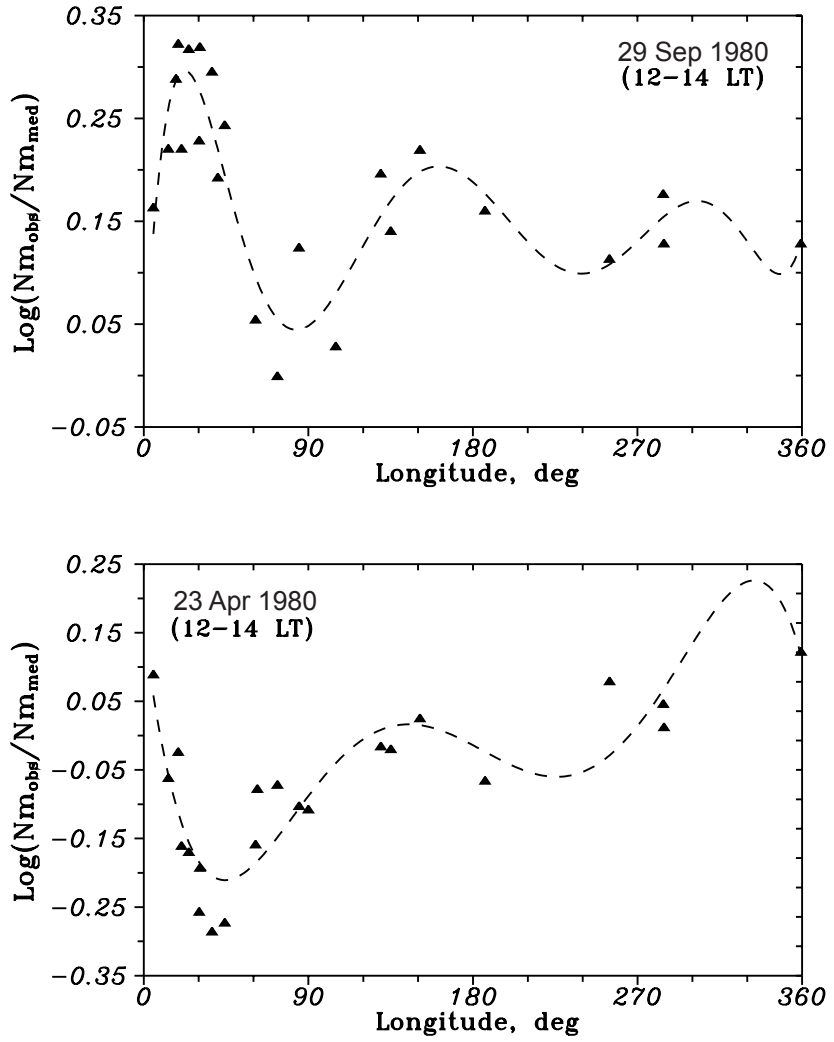

Fig. 5. Longitudinal variation for the amplitude of strong quiet-time NmF2 deviations observed in the European sector on 29 Sep 1980 (positive deviation) and $23 \mathrm{Apr} 1980$ (negative deviation). Northern hemisphere ionosonde stations located in the $50 \pm 5^{\circ}$ latitudinal corridor are used in the analysis. The dashed line represents a polynomial (the $5^{\text {th }}$ order) least squares approximation. Note that maximal and minimal deviations are located in a narrow longitudinal sector.

Let us consider if the same distinctive features can be found for the neighboring days of winter- and summer-like types of diurnal $f o \mathrm{~F} 2$ variation at the time of equinoctial transitions. Unlike continuous ground-based ionosonde $f o \mathrm{~F} 2 \mathrm{ob}-$ servations, IS measurements are not regular and long enough to find pronounced cases of different (winter/summer) type of $f o \mathrm{~F} 2$ variations for magnetically quiet neighboring days. An available (although not well-pronounced) example of 
Table 6. Calculated thermospheric parameters at Millstone Hill compared with MSIS-83 model predictions (second line) at $300 \mathrm{~km}$. $T_{e x}$ values, derived with an algorithm used at Millstone Hill, are given in the third line

\begin{tabular}{lccccc}
\hline Date & $\begin{array}{c}T_{e x} \\
(\mathrm{~K})\end{array}$ & $\begin{array}{c}\log [\mathrm{O}] \\
\left(\mathrm{cm}^{-3}\right)\end{array}$ & $\begin{array}{c}\log \left[\mathrm{O}_{2}\right] \\
\left(\mathrm{cm}^{-3}\right)\end{array}$ & $\begin{array}{c}\log \left[\mathrm{N}_{2}\right] \\
\left(\mathrm{cm}^{-3}\right)\end{array}$ & $\begin{array}{c}W \\
(\mathrm{~m} / \mathrm{s})\end{array}$ \\
\hline 22 Sep 1998 & 1022 & 8.853 & 6.633 & 8.055 & -6.5 \\
$\operatorname{logNmF2}=5.98$ & 1132 & 8.875 & 6.907 & 8.284 & \\
$h m \mathrm{~F} 2=284 \mathrm{~km}$ & 1060 & & & & \\
\hline 23 Sep 1998 & 1074 & 8.657 & 6.607 & 8.066 & +0.2 \\
$\operatorname{logNmF2=5.83}$ & 1160 & 8.885 & 6.960 & 8.321 & \\
$h m \mathrm{~F} 2=290 \mathrm{~km}$ & 1130 & & & & \\
\hline
\end{tabular}

Millstone Hill observations in September 1998 is shown in Fig. 8. The top panel of Fig. 8 gives $f o \mathrm{~F} 2$ variations for 6 consecutive days, while the bottom part shows diurnal variations of $\mathrm{NmF} 2$ and $h m \mathrm{~F} 2$ for two days analyzed with our method. A winter-like (WS) type of the $f o \mathrm{~F} 2$ variation on 22 Sep is followed by a summer (S) one on 23 Sep, both days being magnetically quiet. It is interesting to note that the next day, 24 Sep, was magnetically moderately disturbed $(A p=28)$ but the day-time $f o \mathrm{~F} 2$ values were larger than on $23 \mathrm{Sep}$. A very disturbed day, $25 \mathrm{Sep}$ with low $f o \mathrm{~F} 2$, is followed by a moderately disturbed 26 Sep with a well-pronounced wintertype (WW) foF 2 diurnal variation. In this case, as mentioned earlier, geomagnetic storms seem to stimulate the transition to the other type of diurnal $f o \mathrm{~F} 2$ variation. While day-time $\mathrm{NmF} 2$ values on $22 \mathrm{Sep}$ are greater than on $23 \mathrm{Sep}$, the $h m \mathrm{~F} 2$ values are slightly lower. In general, $22 \mathrm{Sep} / 23 \mathrm{Sep}$ can be regarded as belonging to the analyzed class of events. On one hand they demonstrate the winter/summer transition; on the other hand, 23 Sep may be considered as an example of a quiet-time negative $f o \mathrm{~F} 2$ deviation.

Calculated thermospheric parameters, for the two days at 18 UT (13 LT), are given in Table 6. The most important result is a $57 \%$ decrease in atomic oxygen concentration on 23 Sep with respect to $22 \mathrm{Sep}$, the concentration of molecular species being practically unchanged. The calculated vertical plasma drift, $W$, is also different for the two days corresponding to a northward meridional wind on 22 Sep and being close to zero on $23 \mathrm{Sep}$. The $57 \%$ decrease in [O] at $300 \mathrm{~km}$ corresponds to a depletion of the total atomic oxygen abundance as neutral temperature and neutral scale height are larger on $23 \mathrm{Sep}$. This $T_{e x}$ increase is seen in our calculations, in the values derived at Millstone Hill with a different algorithm (Buonsanto and Pohlman, 1998), as well as in the MSIS- 83 model predictions. The latter however, just reflect a small increase in $A p$ index on $23 \mathrm{Sep}(A p=11)$ compared to $22 \operatorname{Sep}(A p=7)$. Therefore, the selected two days $22 \mathrm{Sep} / 23$ Sep demonstrate thermospheric parameter variations which are typical for WW and SS days, analyzed earlier. The only difference is a small change in molecular species concentrations.

A similar analysis was performed using EISCAT observa-
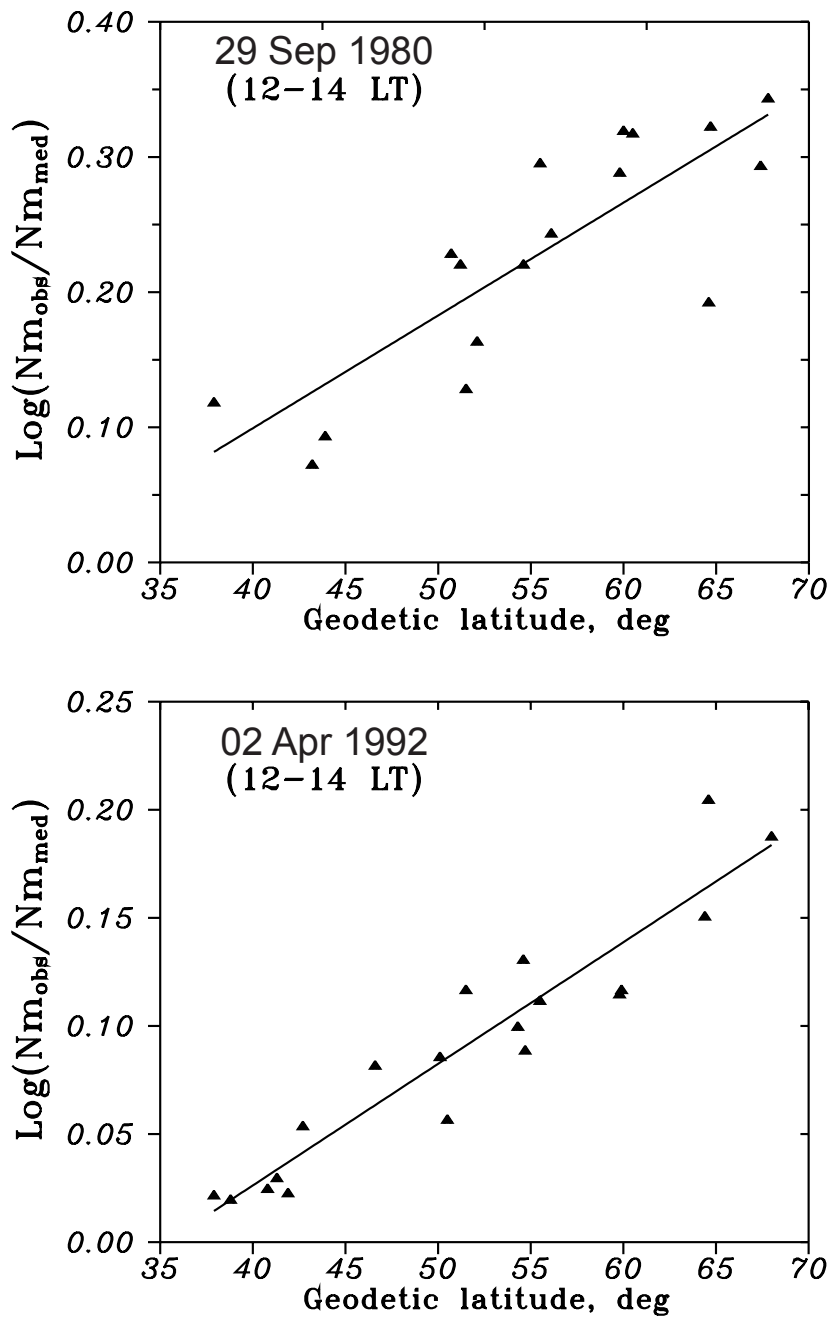

Fig. 6. Latitudinal variation for the amplitude of quiet-time positive NmF2 deviations observed in the European sector on 29 Sep 1980 and 02 Apr 1992. Mostly European ionosonde stations are used to derive the figures.

tions during 31 Mar-03 Apr 1992. This period was previously analyzed by Shepherd et al. (1999) and strong fluctuations in atomic oxygen were revealed from optical observations in the American and European longitudinal sectors. Therefore, an independent comparison for the same period may be interesting. Figure 9 (top panel) gives $f o \mathrm{~F} 2$ variations during the period in question while diurnal variations of $\mathrm{NmF} 2$ and $h m \mathrm{~F} 2$, for the two selected days, are shown in the bottom panels. 02 Apr demonstrates a well-pronounced WW-type diurnal $f o \mathrm{~F} 2$ variation with strongly increased $f o \mathrm{~F} 2$ values compared to the previous days. Although $31 \mathrm{Mar}$ and 01 Apr were slightly disturbed $(A p=14$ and 13$)$, with daytime electric fields of 12 and $7 \mathrm{mV} / \mathrm{m}$ for the two days, the strong $f o \mathrm{~F} 2$ differences between $01 \mathrm{Apr}$ and $02 \mathrm{Apr}$ cannot be attributed to electric field effects. Similar to the 22/23 Sep 1998 case at Millstone Hill, the observed $h m \mathrm{~F} 2$ values are nearly the same for $01 \mathrm{Apr}$ and $02 \mathrm{Apr}$ during day-time hours while the NmF2 values differ by $66 \%$ (Fig. 9, bottom). 

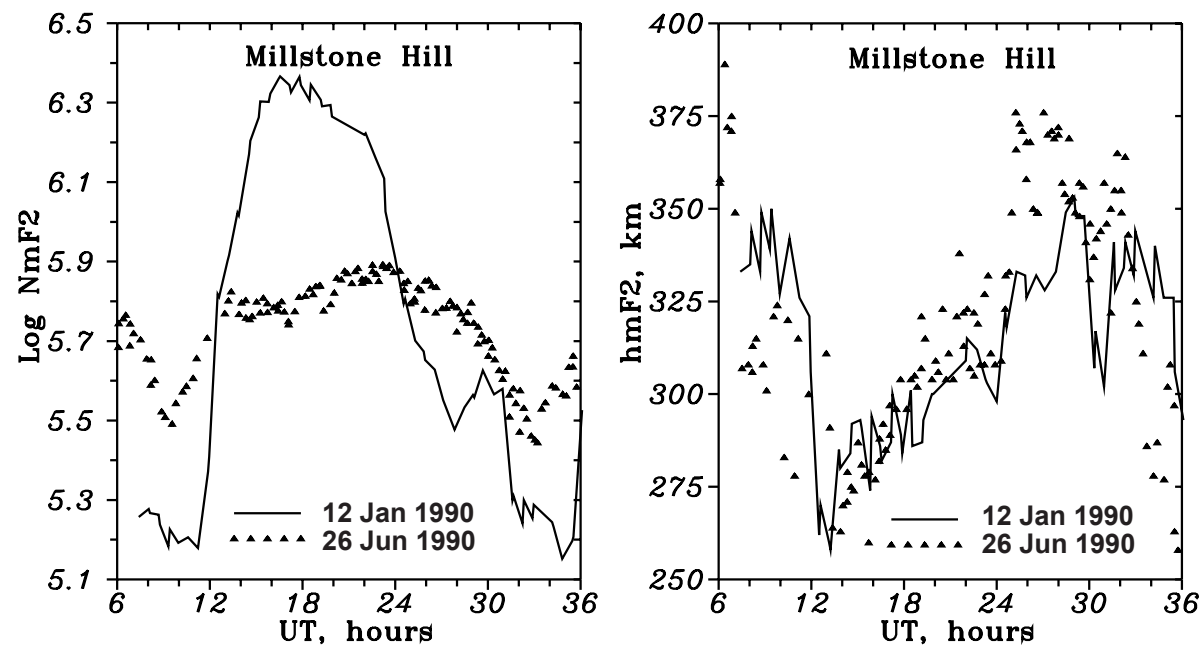

Fig. 7. Diurnal variations of $\mathrm{NmF} 2$ and $h m \mathrm{~F} 2$ observed at Millstone Hill for winter and summer conditions during solar maximum. The selected days illustrate well-pronounced winter (WW) and summer (SS) types of diurnal variations.
Table 7. Calculated thermospheric parameters at EISCAT compared with MSIS-83 model predictions (second line) at $300 \mathrm{~km}$

\begin{tabular}{lccccc}
\hline Date & $\begin{array}{c}T_{e x} \\
(\mathrm{~K})\end{array}$ & $\begin{array}{c}\log [\mathrm{O}] \\
\left(\mathrm{cm}^{-3}\right)\end{array}$ & $\begin{array}{c}\log \left[\mathrm{O}_{2}\right] \\
\left(\mathrm{cm}^{-3}\right)\end{array}$ & $\begin{array}{c}\log \left[\mathrm{N}_{2}\right] \\
\left(\mathrm{cm}^{-3}\right)\end{array}$ & $\begin{array}{c}W \\
(\mathrm{~m} / \mathrm{s})\end{array}$ \\
\hline 01 Apr 1992 & 1241 & 8.798 & 6.956 & 8.412 & +1.6 \\
$\operatorname{logNmF2}=5.89$ & 1337 & 8.836 & 7.214 & 8.506 & \\
$h m \mathrm{~F} 2=301 \mathrm{~km}$ & & & & & \\
\hline 02 Apr 1992 & 1265 & 8.984 & 7.026 & 8.429 & -10.5 \\
$\operatorname{logNmF2=6.11}$ & 1269 & 8.883 & 7.089 & 8.435 & \\
$h m \mathrm{~F} 2=309 \mathrm{~km}$ & & & & & \\
\hline
\end{tabular}

Therefore, the chosen two days also belong to the same class of analyzed events. 02 Apr 1992 represents a good example of a quiet time F2-layer deviation. The results of the thermospheric parameter calculations for the two days at 13 UT (around 14 LT) are given in Table 7.

Analogous to the 22/23 Sep 1998 case, the calculations show a $53 \%$ increase in [O] on $02 \mathrm{Apr}$ with respect to 01 Apr, the concentration of molecular species being practically unchanged. The vertical plasma drift, $W$, is also different for the two days, corresponding to a northward meridional wind of $48 \mathrm{~m} / \mathrm{s}$ on $02 \mathrm{Apr}$ and to a small equatorward wind of $7.4 \mathrm{~m} / \mathrm{s}$ on 01 Apr. The conversion of $W$ to meridional wind is justified at the EISCAT location where the magnetic declination is small $\left(D=1.24^{\circ}\right)$ and the contribution of the zonal thermospheric wind component to $W$ is not essential.

We can conclude that, in the results of both incoherent scatter observations (Millstone Hill and EISCAT), the observed quiet-time $\mathrm{NmF} 2$ deviations are entirely due to the atomic oxygen variation in the thermosphere. The changes of the linear loss coefficient $\beta=k_{1}\left[\mathrm{~N}_{2}\right]+k_{2}\left[\mathrm{O}_{2}\right]$ are small (due to small $\left[\mathrm{O}_{2}\right],\left[\mathrm{N}_{2}\right]$ and reaction rate constants $k_{1}, k_{2}$ variations) and the relative solar EUV flux variations are also small for the neighbouring days. Small $h m \mathrm{~F} 2$ daily variations are due to negligible changes in $\beta$ while the effects of changes in $[\mathrm{O}]$ and $W$ on this quantity are mostly compensated as they work in opposite directions (see later).

\section{Discussion}

Seasonal changes of neutral composition in the thermosphere are due to seasonal variations in global thermospheric circulation, according to present understanding confirmed by 3D model calculations (e.g. Rishbeth and Müller-Wodarg, 1999, and references therein). Summer-to-winter flow of air, directed downwards at subauroral latitudes, enriches the winter hemisphere with atomic oxygen while upward flow in the summer hemisphere decreases the atomic oxygen abundance. In accordance with this concept and with thermospheric wind observations (Wickwar, 1989; Buonsanto and Witasse, 1999) strong poleward wind prevails during all daytime hours in winter, while in summer the meridional wind velocity is much smaller with a direction change from poleward to equatorward soon after 12 LT. Our calculations for days with winter and summer-type diurnal $\mathrm{NmF} 2$ variations reproduce such seasonal changes both in day-time thermospheric wind velocity and in atomic oxygen abundance; i.e. days with winter-type diurnal $\mathrm{NmF} 2$ variation correspond to strong poleward wind and high [O] while summer-type $\mathrm{NmF} 2$ variation corresponds to small (close to zero around 12-14 LT) meridional wind and low atomic oxygen concentration.

The main difference between winter and summer types of diurnal $\mathrm{NmF} 2$ variation is characterized by lower day-time summer NmF2 (seasonal anomaly) and by larger night-time summer NmF2 values compared to winter ones. This results in a low summer $\mathrm{NmF} 2_{\max } / \mathrm{NmF} 2_{\min }$ ratio and a large width of $\mathrm{NmF} 2$ day-time summer variation (SS and $\mathrm{S}$ types) compared to winter ones (WW and W types). The results of our calculations for 12 Jan 1990 and 26 Jun 1990 (Table 5) show this behavior: Winter $[\mathrm{O}]$ values exceed the summer values by $60 \%$ resulting in corresponding differences in the ion production rate $q$. In summer, on the other hand, the linear loss 

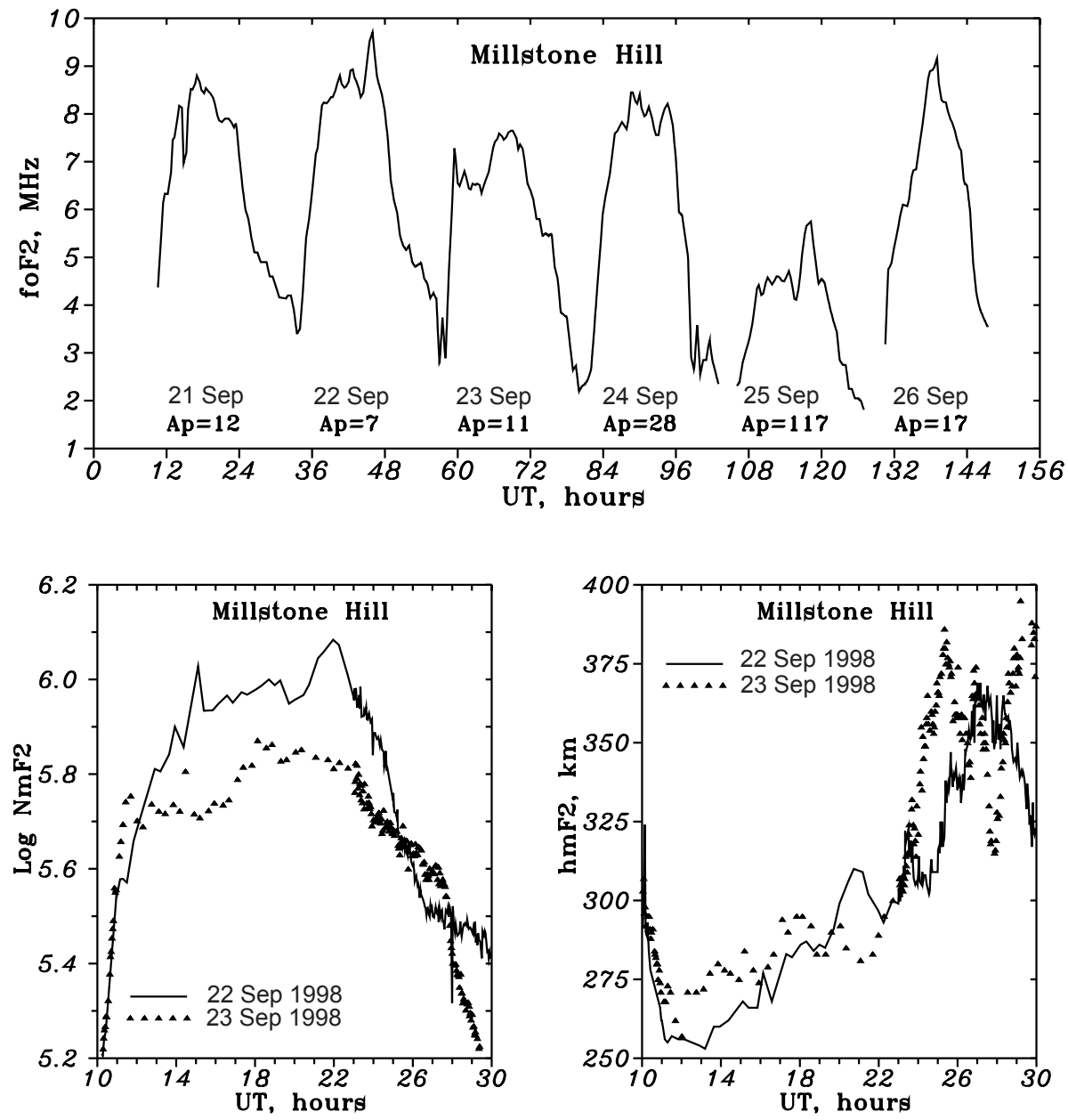

Fig. 8. Daily $f_{o} \mathrm{~F} 2$ variation for successive days during an autumnal transition period at Millstone Hill (top panel). Daily $A p$ indices are given as well. Bottom panels show diurnal $\mathrm{NmF} 2$ and $h m \mathrm{~F} 2$ variations for a winter-like (22 Sep 1998) and summer-like (23 Sep 1998) day analyzed for thermospheric parameter variations $(\mathrm{LT}=\mathrm{UT}-5)$. coefficient $\beta$ is $68 \%$ larger due to higher temperature and molecular species concentrations. Low $q$ and large $\beta$ result in low summer NmF2. This is the well-known explanation of the F2-layer seasonal anomaly.

The role of vibrationally excited $\mathrm{N}_{2}^{*}$ in reducing summer NmF2 is also discussed in the literature (Pavlov, 1986; Ennis et al., 1995; Pavlov et al., 1999, and references therein). In accordance with the results of our previous analysis (Mikhailov and Schlegel, 2000) we use, in our model calculations, recent laboratory measurements of the $\mathrm{O}^{+}+\mathrm{N}_{2}$ reaction rate constant (Hierl et al., 1997) which takes the vibrationally excited $\mathrm{N}_{2}^{*}$ into account. For the night, there is no seasonal F2-region anomaly; i.e. night-time summer NmF2 values are higher than the corresponding winter values. This results in a seasonal difference of $\mathrm{NmF} 2{ }_{\max } / \mathrm{NmF} 2_{\text {min }}$, as observed. This effect is not related to seasonal variations of neutral composition but is due to a different diurnal variation of thermospheric winds during winter and summer (IvanovKholodny and Mikhailov, 1986).

During the transition, we never observed, on adjacent days, such strong diurnal $\mathrm{NmF} 2$ variations as those shown in Fig. 7 for the completely developed WW- and SS-types on 12 Jan and 26 Jun 1990. Nevertheless, two distinctive features - a strong decrease (or even reversal) of the normal solar driven northward wind and a decrease in atomic oxygen abundance are present in the analyzed $22 \mathrm{Sep} / 23 \mathrm{Sep} 1998$ and $01 \mathrm{Apr} / 02$ Apr 1992 cases. In both cases, the difference in the observed day-time $\mathrm{NmF} 2$ variations is almost all due to changes in atomic oxygen concentration. Variations of $\left[\mathrm{N}_{2}\right],\left[\mathrm{O}_{2}\right]$ and $T_{n}$ are small (Tables 6 and 7). This is different from a strongly developed Winter (WW)/Summer(SS) case. For neighboring days, during transition periods like 22 Sep/23 Sep 1998 and 01 Apr/02 Apr 1992, changes in the linear loss coefficient $\beta$ are small and $h m \mathrm{~F} 2$ day-to-day variations result from a competition between [O] and $W$ as they work in opposite directions. This can be seen from an approximate expression for day-time $h m \mathrm{~F} 2$ (Ivanov-Kholodny and Mikhailov, 1986) which, for constant $T_{e x}$, may be written as:

$\Delta h m \mathrm{~F} 2=H / 3 \Delta \ln [\mathrm{O}]+H / 3 \Delta \ln \beta+c \Delta W$

where $H$ is the neutral scale height for atomic oxygen, $W$ (in $\mathrm{m} / \mathrm{s}$ ) is the vertical plasma drift, positive upward, and $c$ is a coefficient around 1.0-1.5. This qualitative expression illustrates the competition between the [O] and $W$ contributions. Depending on [O] and $W$, day-to-day changes of $\Delta h m \mathrm{~F} 2$ may be positive or negative (cf. Tables 6 and 7 , also Figs. 2 and 3). 

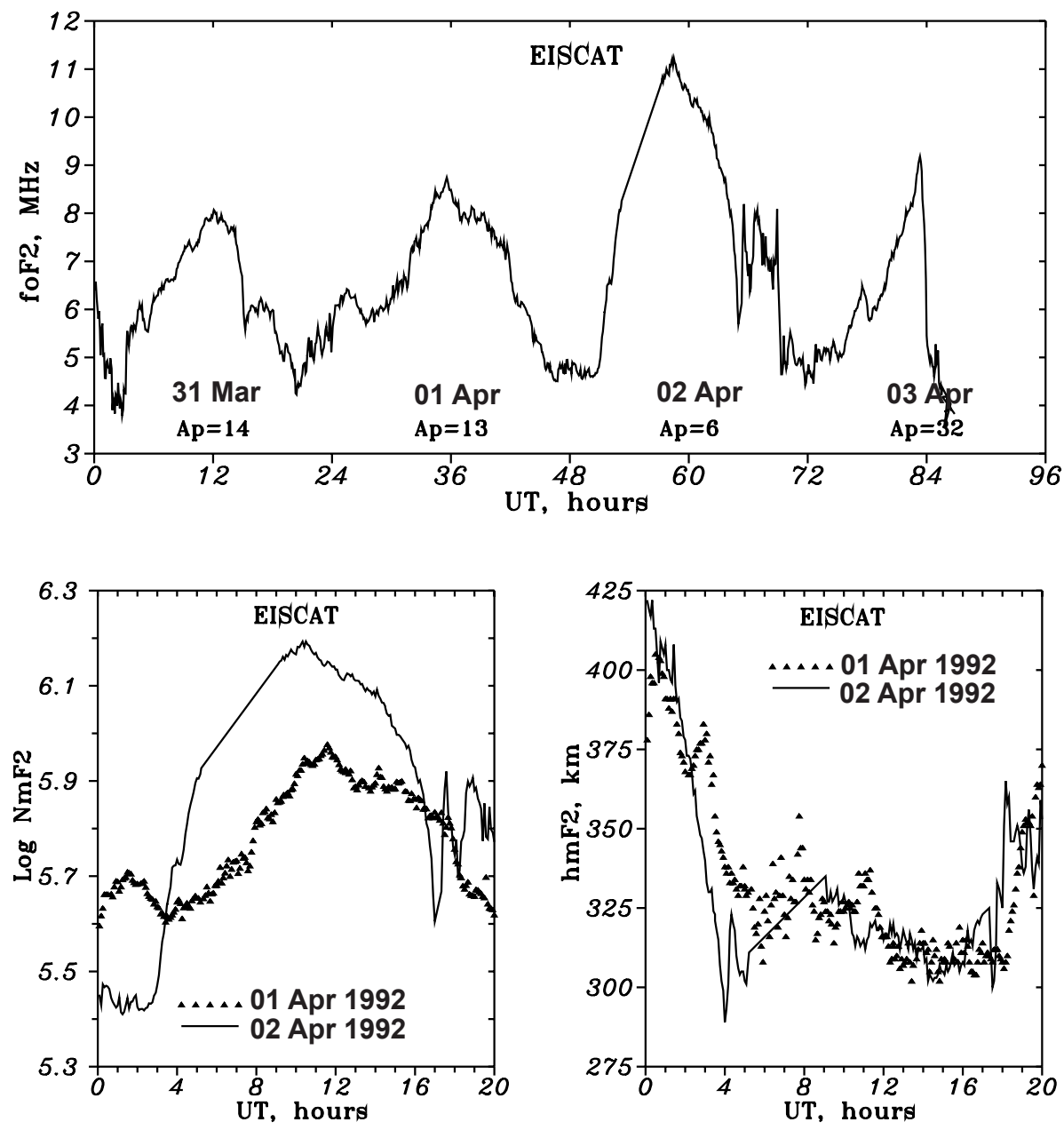

Fig. 9. Daily foF2 variation for successive days during a vernal transition period at EISCAT (top panel). Daily $A p$ indices are also given. Bottom panels show diurnal $\mathrm{NmF} 2$ and $h m \mathrm{~F} 2$ variations for a winter-like (02 Apr 1992) and summer-like (01 Apr 1992) day analyzed for thermospheric parameter variations $(\mathrm{LT}=\mathrm{UT}-1.3)$.
Shepherd et al. (1999) observed large variations of atomic oxygen concentration in the lower $\mathrm{E}$ region and related these to vertical air motions. Downward mass motion increases the atomic oxygen abundance while upward motion depletes the thermospheric [O] abundance. Using Millstone Hill IS observations it was shown by Ivanov-Kholodny et al. (1981) that day-to-day $\mathrm{NmF} 2$ and $h m \mathrm{~F} 2$ variations are in phase in summer and that they are accompanied by similar variations in $f o \mathrm{E}$. The effect of simultaneous changes of electron concentration in the ionospheric $\mathrm{E}$ and $\mathrm{F} 2$-regions was also theoretically modeled by Mikhailov (1983) who showed that such variations can be explained by day-to-day changes in vertical mass velocity of about $1-2 \mathrm{~cm} \mathrm{~s}^{-1}$ at E-region heights, resulting in $[\mathrm{O}]$ and $\left[\mathrm{O}_{2}\right]$ anti-phase changes. The results of those model calculations yielded day-to-day variations at $300 \mathrm{~km}$ for neighbouring days of $\Delta \log [\mathrm{O}] \approx 0.2(58 \%)$, $\Delta \log \left[\mathrm{O}_{2}\right] \approx 0.08(20 \%)$, and $\Delta \log \left[\mathrm{N}_{2}\right] \approx 0.01$. The latter results in very small changes of the linear loss coefficient $\beta$. Such variations of $[\mathrm{O}]$ and $\beta$ agree with the results of our present calculations of the thermospheric parameter changes for 22 Sep/23 Sep 1998 and 01 Apr/02 Apr 1992 (Tables 6 and 7).

It should be noted that in our model is no provision to con- trol mass conservation, since it is assumed that this is accomplished in the lower thermosphere (below $160 \mathrm{~km}$ height) where our method is not applied. Mass conservation can only be strictly achieved in a full 3-D model, whereas ours is essentially a 1-D model. In previous calculations (Mikhailov, 1983) for a stationary thermosphere, the contribution of [O] and $\left[\mathrm{O}_{2}\right]$ changes (due to the difference in mass numbers) to the total gas density compensated each other to a large extent. In our present case, the calculated $\left[\mathrm{O}_{2}\right]$ changes are small and do not compensate the [O] variations (Tables 6 and 7). This may be a consequence of the limited accuracy of our method which is about $20 \%$ for the main species $\mathrm{O}$ and $\mathrm{N}_{2}$ (Mikhailov and Schlegel, 1997). The accuracy of the $\left[\mathrm{O}_{2}\right]$ estimate should be even smaller since the $\mathrm{O}_{2}$ contribution to the $N_{e}(h)$ formation is relatively small at F2-region heights. On the other hand, it should be kept in mind that day-today changes of 35-40\% in the total gas density (mostly due to $[\mathrm{O}]$ variations) at the F2-region heights may be regarded as a feature of a moving planetary wave (Fig. 5). Dynamical wave structure implies nodes and extrema in total density and pressure; therefore, the neutral species may not be in a diffusive equilibrium. Variations in the thermospheric total gas density of the same order of magnitude were observed, 
for instance, by ESRO-4 (Prölss, 1982) and by DE-2 (Burns and Killeen, 1992).

An analysis of WINDII observations of the oxygen green line emission rate by Ward et al. (1997) revealed vertical motions associated with a quasi-two day wave at E-region heights. Mean vertical winds of a few $\mathrm{cm} \mathrm{s}^{-1}$ have been deduced from the WINDII data by Fauliot et al. (1997). Similarly, ground-based radar observations by Voiculescu et al. (1999) proved a strong influence of the planetary quasi 2day wave on the mid-latitude E region. At F2-region heights, quasi 2-day oscillations in $\mathrm{NmF} 2$ are widely discussed in the literature (e.g. Apostolov et al., 1995; Forbes et al., 1997 and references therein). Unfortunately, Millstone Hill observations are not available at E-region heights for the analyzed period 22/23 Sep 1998 and particle precipitation perturbs the auroral E-region (EISCAT location) even during rather quiet time periods. Therefore, it was not possible to check the presence of simultaneous electron density changes in E and F2 regions for the two periods in question. But such an analysis is possible with mid-latitude ground-based ionosonde observations as performed by Mikhailov (1983).

The quiet-time $\mathrm{NmF} 2$ deviations during the transition periods and its seasonal (Fig. 4) and spatial (Figs. 5 and 6) dependencies have been described in detail in Sect. 3. On the one hand, such strong NmF2 deviations, of up to a factor of 2 as on 29 Sep and 23 Apr 1980 (Figs. 2 and 3), are comparable with F2-layer storm effects related to strong geomagnetic disturbances but their mechanism is different from usual F2-layer storm effects outlined above. On the other hand, the spatial variations of their amplitude may tell us about longitudinal and latitudinal variations of the thermospheric circulation pattern during the transition periods. The effect may be related to quasi 2-day oscillations occurring mainly during summer but with maximum amplitudes during equinoxes (Forbes et al., 1992). Indeed, Fig. 4 shows that strong quiet time $\mathrm{NmF} 2$ deviations are most probable around equinoxes. A well-pronounced wave-like longitudinal structure of such deviations (Fig. 5), with maxima and minima located in rather narrow longitudinal sectors, obviously reflects the corresponding longitudinal structure in thermospheric winds during the transition periods. Obviously, the revealed effect of the quiet-time F2-region deviations needs further analysis using the world-wide ionosonde network together with IS and optical observations.

\section{Conclusions}

The main results of our analysis can be summarized as follows:

1. The transitions from winter to summer-type diurnal $f o \mathrm{~F} 2$ variation, averaged for 6 stations and years of solar maximum and minimum, occur during 20-25 days; the vernal transition lasts a little longer than the autumnal one. The vernal transition starts close to the equinox while the autumnal one starts earlier. Both transitions start a little earlier during solar minimum and last longer compared to solar max- imum. This may be due to stronger thermospheric winds and less inertia of the thermosphere during solar minimum. Cases of very fast (6-10 days) transitions are revealed at particular stations. Neither latitudinal nor longitudinal variations, for the dates and duration of the transitions, could be derived within the available accuracy of these parameters.

2. Strong (up to a factor of 2) day-time NmF2 deviations of both signs, not related to geomagnetic activity, are revealed for the transitions. Both negative and positive deviations cluster around equinoxes suggesting a relationship with the equinoctial transitions in the F2-region. The actual number of positive and negative deviations varies from year to year but no regularity has been found. There are years $(1960,1973,1974)$ when only positive deviations took place but negative deviations prevailed in 1962, 1967, 1970.

3. The longitudinal variation pattern of such quiet-time $\mathrm{NmF} 2$ deviations resembles a wave with a steep front since both maximum and minimum $\mathrm{NmF} 2_{\text {obs }} / \mathrm{NmF} 2_{\text {med }}$ values are located in a narrow longitudinal interval. A well-pronounced latitudinal increase of the amplitude of the $\mathrm{NmF} 2$ deviation was observed for cases of positive NmF2 deviations. No latitudinal dependence was found for negative $\mathrm{NmF} 2$ deviations.

4. Estimates of thermospheric parameters, using EISCAT and Millstone Hill IS observations for adjacent days during the transition periods with different type of diurnal $\mathrm{NmF} 2$ variations, have shown that summer-like days are distinguished by decreased (by $\approx 55 \%$ ) atomic oxygen concentration compared to winter-like days, molecular $\mathrm{N}_{2}$ and $\mathrm{O}_{2}$ concentrations being almost unchanged day-time meridional thermospheric wind (inferred from vertical plasma drift $W$ ) is small and equatorward for summer-like days unlike the strong northward winds for winter-like days. Therefore, the observed quiet-time $\mathrm{NmF} 2$ deviations are entirely due to the atomic oxygen variation in the thermosphere as the linear loss coefficient $\beta=k_{1}\left[\mathrm{~N}_{2}\right]+k_{2}\left[\mathrm{O}_{2}\right]$ variations are small (due to small $\left[\mathrm{O}_{2}\right],\left[\mathrm{N}_{2}\right]$ and reaction rate constants $k_{1}, k_{2}$ variations). Relative solar EUV flux variations are also small for the adjacent days. Small $h m \mathrm{~F} 2$ day-to-day variations are due to negligible variation in $\beta$ while the effects of $[\mathrm{O}]$ and $W$ changes are compensated to a large extent as they work in opposite directions.

5. The main mechanism of day-to-day $\mathrm{NmF} 2$ variations, during the transition periods resulting in winter/summer-like type of diurnal $\mathrm{NmF} 2$ variation as well as in $\mathrm{NmF} 2$ quiet time deviations, is the change in atomic oxygen abundance in the thermosphere. Such variations of atomic oxygen take place both at $\mathrm{E}$ and F2-region heights as they follow from direct optical observations in the lower thermosphere and incoherent scatter data analysis in the F2-region. The most probable reason for such variations is a change in the global circulation pattern manifested by day-to-day changes of the meridional wind in the F2-region and by vertical mass velocity variations inferred from observations at E-region heights.

Acknowledgements. The authors thank the Millstone Hill Group of the Massachusetts Institute of Technology, Westford; also the Director and the staff of EISCAT for running the radar and pro- 
viding the data. The EISCAT Scientific Association is funded by scientific agencies of Finland (SA), France (CNRC), Germany (MPG), Japan (NIPR), Norway (NF), Sweden (NFR) and the United Kingdom (PPARC). This work was supported under NATO grant EST.EV.976711.

Topical Editor M. Lester thanks A. C. Schlesier and another referee for their help in evaluating this paper.

\section{References}

Apostolov, E. M., Altadill, D., and Alberca, L., Characteristics of quasi-2-day oscillations in the $f o \mathrm{~F} 2$ at northern middle latitudes, J. Geophys. Res., 100, 12163-12171, 1995.

Bradley, P. A. and Dudeney, J. R., A simple model of the vertical distribution of electron concentration in the ionosphere, J. Atmos. Terr. Phys., 35, 2131-2146, 1973.

Buonsanto, M. J. and Pohlman, L. M., Climatology of neutral exospheric temperature above Millstone Hill, J. Geophys. Res., 103, 23381-23392, 1998

Buonsanto, M. J. and Witasse, O. G., An update climatology of thermospheric neutral winds and $\mathrm{F}$ region ion drifts above Millstone Hill, J. Geophys. Res., 104, 24675-24687, 1999.

Burns, A. G. and Killeen, T. L., The equatorial neutral thermospheric response to geomagnetic forcing, Geophys. Res. Lett., 19, 977-980, 1992.

Ennis, A. E., Bailey, G. J., and Moffett, R. J., Vibrational nitrogen concentration in the ionosphere and its dependence on season and solar cycle, Ann. Geophysicae, 13, 1164-1171, 1995.

Evans, J. V., Millstone-Hill Thomson scatter results for 1965, Planet. Space Sci, 18, 1225-1252, 1970.

Evans, J. V., Millstone-Hill Thomson scatter results for 1966 and 1967, Planet. Space Sci., 21, 763-792, 1973.

Evans, J. V., Millstone-Hill Thomson scatter results for 1969, Lincoln Lab., M.I.I., Lexington, Mass. Tech. Rep., N 513, 1974.

Forbes, J. M., Guffee, R., Zhang, X., Fritts, D., Riggin, D., Manson, A., Meek, C., and Vincent, R. A., Quasi 2-day oscillation of the ionosphere during summer 1992, J. Geophys. Res., 102, 73017305, 1997.

Fauliot, V., Thuillier, G., and Vial, F., Mean vertical wind in the mesosphere-lower thermosphere region $(80-120 \mathrm{~km})$ deduced from the WINDII observations on board UARS, Ann. Geophysicae, 15, 1221-1231, 1997.

Fuller-Rowell, T. J. and Rees, D., Derivation of a conservation equation for mean molecular weight for a two-constituent gas within a three-dimensional, time-dependent model of the thermosphere, Planet. Space Sci., 31, 1209-1222, 1983.

Hierl, P. M., Dotan, I., Seeley, J. V., Van Doran, J. M., Morris, R. A., and Viggiano, A. A., Rate coefficients for the reactions of $\mathrm{O}^{+}$with $\mathrm{N}_{2}$ and $\mathrm{O}_{2}$ as a function of temperature $(300-188 \mathrm{~K}$ ), J. Chem. Phys., 106 (9), 3540-3544, 1997.

Ivanov-Kholodny, G. S., Mikhailov, A. V., and Ostrovskiy, G. I., Day-to-day change in the summer values of $h m \mathrm{~F} 2$ and $\mathrm{NmF} 2$ as a reflection of variations in the neutral composition of the upper atmosphere, Geomagn. Aeronom., 21, 615-617, 1981.
Ivanov-Kholodny, G. S. and Mikhailov, A. V., The prediction of ionospheric conditions, D. Reidel Publ. Co., Dordrecht, Holland, 1986.

Mikhailov, A. V., Possible mechanism for the in-phase changes in the electron densities in the ionospheric $\mathrm{E}$ and $\mathrm{F} 2$ regions, Geomagn. Aeronom., 23, 455-458, 1983.

Mikhailov, A. V. and Förster, M., Some F2-layer effects during the 06-11 January 1997 CEDAR storm period as observed with the Millstone Hill incoherent scatter facility, J. Atmos. Solar-Terr. Phys., 61, 249-261, 1999.

Mikhailov, A. V. and Schlegel, K., Self-consistent modeling of the day-time electron density profile in the ionospheric F-region, Ann. Geophysicae, 15, 314-326, 1997.

Mikhailov, A. V. and Schlegel, K., A self-consistent estimate of $\mathrm{O}^{+}+\mathrm{N}_{2}$ rate coefficient and total EUV solar flux with $\lambda<1050$ $\AA$ using EISCAT observations, Ann. Geophysicae, 18, 1164 1171, 2000.

Pavlov, A. V., Rate coefficient of $\mathrm{O}^{+}$with vibrationally excited $\mathrm{N}_{2}$ in the ionosphere, Geomag. i Aeronom., 26, 166-168, 1986 (in Russian)

Pavlov, A. V., Buonsanto, M. J., Schlesier, A. C., and Richards, P. G., Comparison of models and data at Millstone Hill during the 5-11 June 1991 storm, J. Atmos. Solar-Terr. Phys., 61, 263-279, 1999.

Prölss, Perturbation of the low-latitude upper atmosphere during magnetic substorm activity, J. Geophys. Res., 87, 5260-5266, 1982.

Rishbeth, H. and Setty, C. S. G. K., The F-layer at sunrise, J. Atmos. Terr. Phys., 21, 263-276, 1961.

Rishbeth, H. and Müller-Wodarg, I. C. F., Vertical circulation and thermospheric composition: a modelling study, Ann. Geophysicae, 17, 794-805, 1999.

Shepherd, G. G., Stegman, J., Espy, P., McLandress, C., Thuillier, G., and Wiens, R. H., Springtime transition in lower thermospheric atomic oxygen, J. Geophys. Res., 104, 213-223, 1999.

Torr, M. R. and Torr, D. G., The seasonal behavior of the F2-layer of the ionosphere, J. Atmos. Terr. Phys., 35, 2237-2251, 1973.

Voiculescu, M., Haldoupis, C., and Schlegel, K., Evidence for planetary wave effects on midlatitude backscatter and sporadic $\mathrm{E}$ layer occurrence, Geophys. Res. Lett., 26, 1105-1108, 1999.

Ward, W. E, Solheim, B. H., and Shepher, G. G., Two day wave induced variations in the oxygen green line volume emission rate: WINDII observations, Geophys. Res. Lett., 24, 1227-1130, 1997.

Wickwar, V. B., Global thermospheric studies of neutral dynamics using incoherent scatter radars, Adv. Space Res., 9, 87-102, 1989.

Yonezawa, T., On the seasonal and non-seasonal annual variations and the semi-annual variation in the noon and midnight electron density of the F2layer in middle latitudes, J. Radio Res. Labs., 6 , 651-668, 1959.

Yonezawa, T. and Arima, Y., On the seasonal and non-seasonal annual variations and the semi-annual variation in the noon and midnight electron density of the F2layer in middle latitudes, J. Radio Res. Labs., 6, 293-309, 1959. 